Original Research Paper

\title{
Juvenile Court Dispositions in the Deep South: Examining the Concept of Justice by Geography
}

\author{
${ }^{1}$ Bret Blackmon, ${ }^{2}$ Daphne S. Cain and ${ }^{3}$ Michelle Livermore \\ ${ }^{1}$ School of Social Work, The University of Southern Mississippi, Mississippi, USA \\ ${ }^{2}$ Department of Social Work, University of Mississippi, Mississippi, USA \\ ${ }^{3}$ School of Social Work, Louisiana State University, Louisiana, USA
}

Article history

Received: 15-01-2015

Revised: 11-05-2015

Accepted: 06-06-2015

Corresponding Author:

Bret Blackmon

School of Social Work, The

University of Southern

Mississippi, Mississippi, USA

Email: bret.blackmon $@$ usm.edu

\begin{abstract}
The concept of justice by geography suggests that sentencing decisions in the juvenile justice system are influenced by the geographical context of the courts. This study sought to examine this phenomenon by examining rates of harsh juvenile sentencing (dispositions) in 64 parishes (i.e., counties) in the Deep South using parish-level characteristics such as geographic location (urban/suburban vs. rural), race and poverty. A multivariate regression analysis revealed that places with high poverty rates experienced significantly higher harsh disposition rates than those with less poverty. Other measured parish characteristics were unrelated and thus, the justice by geography concept was not supported. Implications for juvenile justice policy and future research are discussed.
\end{abstract}

Keywords: Juvenile Court, Delinquency, Dispositions, Poverty, Deep South

\section{Introduction}

Juvenile Court Dispositions in the Deep South: Examining the Concept of Justice by Geography

Juvenile delinquency remains a problem across the United States and is prevalent in both urban and rural regions of the country (Puzzanchera, 2009). The "get tough" policies of the 1990s resulted in federal and state legislation which gave much discretion to juvenile court judges in rendering dispositions (The term 'dispositions' is congruent with the term juvenile court sentences. This term was adopted to decriminalize the juvenile justice system in the U.S) (Snyder and Sickmund, 2006). Previous research has found disparities in youth dispositions and suggested that individual, legal and environmental factors influence case processing and final dispositions (Cauffman et al., 2007; Feld, 1991). Also, dispositions have been found to vary across geographical contexts (Cauffman, et al., 2007; Cohen and Kluegel, 2001; Feld, 1991). This phenomenon was coined justice by geography in a 1991 study (Feld). The current study sought to build upon previous research by examining how environmental factors such as geographic location (urban/suburban and rural), poverty level and racial composition influence juvenile court dispositions.

\section{Scope of Problem: Juvenile Delinquency}

In 2009, U.S. law enforcement agencies arrested approximately 1.9 million juveniles (Puzzanchera and Adams, 2011). Although this figure marks a $17 \%$ decrease since 2000 , murder rates remained stable and robbery rates increased by $15 \%$. Youth offenders accounted for $15 \%$ of all violent crime arrests and $24 \%$ of all property offenses in 2009 (Puzzanchera and Adams, 2011). Most arrested juveniles were referred to court $(67 \%)$ while $22 \%$ were processed and released by local law enforcement agencies according to 2009 national statistics (Puzzanchera and Adams, 2011). More than 31 million youth remain in juvenile court jurisdiction in the U.S. (Puzzanchera and Hockenberry, 2013). Juvenile courts handled $1,368,200$ delinquency cases in 2010, which reflects a $17 \%$ increase since 1985 (Puzzanchera and Hockenberry, 2013). Court statistics indicated an increase of $17 \%$ in cases involving detention and a 7\% increase in out-home-placement dispositions (Puzzanchera and Hockenberry, 2013).

In regard to adjudicated offenders, there were 92,000 delinquents held in residential facilities in 2003, an $8 \%$ decrease since 1997 (Snyder and Sickmund, 2006). However, 26 states experienced an increase in their rates of juveniles placed in detention facilities. The five states with the highest detention rates in 2003 were Louisiana, 
Nevada, Arizona, Alaska and California (Snyder and Sickmund, 2006). Louisiana, a Deep South state, is the focus of this study.

\section{Why Louisiana?}

In addition to having one of the highest detention rates in the country and ranking sixth highest in juvenile crime in 2003, Louisiana was the only state in the southeast region of the United States to maintain a high proportion of juveniles in secure-care facilities (LCLE, 2007; Snyder and Sickmund, 2006). In 2003, approximately 136 out of every 100,000 juveniles in Louisiana were housed in detention sites. Compared to Texas, Louisiana almost doubled the proportion of juveniles housed in detention (Snyder and Sickmund, 2006). Also, Louisiana's legislative statutes give supreme discretion to the courts in sentencing juveniles while providing minimal formal oversight to ensure judges make the most appropriate decisions (NCJJ, 2005).

Juvenile court policies vary from parish to parish in Louisiana (Louisiana is divided into parishes in the same way other states are divided into counties). The primary source of Louisiana statutes regarding court proceedings are outlined in the Children's Code (NCJJ, 2005). Prior to recent reforms, this code did not set specific guidelines in terms of detaining youth, in-take screening, diversion programs, predisposition investigations, committing youth to the state and releasing youth. These local courts established their own policies based on their resources and personnel. Louisiana courts were not required to use risk assessment instruments to guide their decision-making until 2010 when the Structured Assessment of Violence Risk in Youth (SAVRY) was adopted to address high recidivism rates (LAOJJ, n.d.; NCJJ, 2005). Furthermore, no formal oversight mechanism existed to overrule juvenile court judges' dispositions (NCJJ, 2005). Legislative reforms in 2003 authorized the establishment a risk review panel through the Louisiana Office of Juvenile Justice with a purpose to ensure least restrictive placements among delinquents. However, the court with original jurisdiction continued to maintain the ultimate authority to modify or deny this panel's recommendations (NCJJ, 2005).

The discretion of Louisiana juvenile court judges is highlighted by the state's juvenile waiver laws (Snyder and Sickmund, 2006). Louisiana law uniquely allows for three different types of juvenile waivers to adult court. These waivers include judicial waivers, prosecutorial waivers and statutory exclusion. Judicial waivers, the most common type, occur when juvenile court judges use their discretion to refer a case to adult court. Prosecutorial waivers, which enables the prosecutor to determine whether or not the youth should be tried in adult court, are only allowed in only 14 other states. Statutory exclusion refers to state laws that set clear criteria in transferring youth to adult court based on their age and the nature of the crime (Snyder and Sickmund, 2006). Overall, these waiver laws create an environment where juvenile delinquents are at increased risk of harsh sanctioning.

The Louisiana juvenile justice system has experienced instability over the last twenty years. During the 1990s, Louisiana had the highest juvenile incarceration rate in the entire country (LAOJJ, n.d.). There were dramatic inconsistencies in sentencing among judges, high recidivism rates, high numbers of juveniles being tried as adults, disproportionate minority contact ('Disproportionate minority contact' refers to the disproportionate number of minorities that come into contact with Louisiana's juvenile justice system) and overcrowded secure-care facilities. A 1996 federal investigation into Louisiana juvenile detention facilities led to a federal lawsuit accusing these institutions of failing to provide a safe environment and failing to meet the medical, mental health and rehabilitative needs of offenders (LAOJJ, n.d.). The lawsuit led to major reform efforts that resulted in the Louisiana Juvenile Justice Reform Act of 2003. This piece of legislation provided the conceptual framework for transforming Louisiana from a punitive juvenile court system to a rehabilitative system of care. Specifically, these reforms sought to increase the number of community based services, reduce numbers in secure care facilities, involve families in decision-making processes, conduct strengths-based assessments and utilize individual service plans to prevent youth crime and reduce recidivism rates. In 2006, the federal investigation was dropped and charges were dismissed due to Louisiana's reform efforts (LAOJJ, n.d.).

The Louisiana Juvenile Justice Reform Act (2003) led to a substantial transformation of Louisiana's juvenile justice system. Since 2003, more resources have been dedicated to diversion and prevention activities, while services like day treatment, mentoring, counseling and summer activities have been expanded. The securecare facilities that led to the federal lawsuit have been converted into state-of-the-art regional facilities that provide on-site educational, vocational, medical, dental and mental health services. Specialized residential facilities have also been developed to meet the needs of juvenile sexual offenders and substance abusers. Other reforms have emphasized safety, family involvement, a continuum of care, community involvement and datadriven outcomes (LAOJJ, n.d.). As a testament to these reforms, Louisiana was chosen as one of the MacArthur Foundation's Models for Change sites.

Louisiana provides an ideal environment to examine the differences in juvenile court dispositions due to the high level of court discretion, volatile history and recent reforms. The authors analyzed juvenile court data from 
each parish in Louisiana and hypothesized that urban/suburban parishes with high poverty rates and minority status rates would be more likely to render harsher dispositions on juvenile offenders.

\section{Literature Review}

\section{Environmental Influences}

Justice by geography is a term coined by Feld (1991) that refers to disparities in juvenile court decision making due to the geographic location of the court and sociopolitical factors within that environment. In a sample of all the youth involved in the criminal justice system across Minnesota, Feld (1991) compared courts based on their geographic location in urban, suburban, or rural counties. He found that court dispositions varied based on location and that urban courts were more likely to enact harsher dispositions than rural courts. Feld's results indicated that urban courts were more due process oriented than rural courts, which explained the variance in sentencing (Feld, 1991). Although Feld's study laid the groundwork for understanding how non-legal factors influence court decisions, more recent studies focused on individual-level variables and yielded conflicting results.

In contrast to Feld (1991) study, Sanborn (2001) found that courts did not vary due to their location. By interviewing court personnel from urban, suburban and rural courts in northeastern states, Sanborn found that variations occurred within courts rather than between courts. Specifically, he found that judges' sentencing disparities occurred due to their philosophy and approach rather than by geographic location (Sanborn, 2001). These findings, however, revealed some variation in court workers' perceptions of judges. Urban workers were much more critical of judges as evidenced by their reports that the judges did not receive necessary training to treat delinquents and regularly failed to fulfill their obligations to the youth (Sanborn, 2001).

A 1995 study indicated that rural county court judges with general jurisdiction were more likely to implement harsh sanctions than specialized juvenile courts in urban counties (Johnson and Secret, 1995). Findings also showed that many juvenile delinquents were unfairly treated in rural counties due to the courts' structure. These researchers suggested that many of the offenders would likely have not been adjudicated delinquent in specialized urban, juvenile courts (Johnson and Secret, 1995).

There are few studies that have explored county-level variations among juvenile courts for an entire state, but the available studies indicated strong county disparities regarding juvenile dispositions (Feld, 1991; Johnson and Secret, 1995). Due to feasibility reasons, most studies have compared only two juvenile courts from different locations. Although external validity was limited, these studies have identified strong discrepancies in adjudicating and sentencing juveniles (Cauffman et al., 2007; Cohen and Kluegel, 2001; Guevara et al., 2008). A 2007 study, for instance, compared two juvenile courts from large metropolitan areas in Phoenix and Philadelphia (Cauffman et al., 2007). Findings revealed inconsistent sanctions between the two courts. Violent juvenile offenders in Phoenix were more likely to be placed in secure facilities than in Philadelphia (Cauffman et al., 2007). Cohen and Kluegel (2001) found similar discrepancies in comparing two juvenile courts from Memphis, TN and Denver, CO. The researchers found that Memphis' more traditional orientation to juvenile justice resulted in the detainment of a higher overall number of juveniles than in Denver. Denver's more due process oriented court, however, detained more status offenders than in Memphis (Cohen and Kluegel, 2001).

\section{Legal and Individual Influences}

Other studies have focused on the legal determinants of juvenile sentencing. Arrest histories and offense characteristics have been highly correlated with harsh dispositions resulting in secure placements (Applegate et al., 2002; Cauffman et al., 2007). Studies have also shown that the presence of legal counsel has been correlated with harsher sanctions (Feld, 1991; Guevara et al., 2008).

In addition to legal influences, individual characteristics may also predict harsh sanctioning. Although studies have produced mixed findings, research has demonstrated a connection between race, poverty, gender and harsh sanctioning (Dejong and Jackson, 1998; Sampson and Laub, 1993; Webb, 2006). In a 2006 study, Webb found that race was the most influential factor in predicting harsh dispositions when controlling for legal and non legal factors. In his study, black juveniles received pretrial detention almost twice as much as white juveniles and a significantly higher proportion of males were assigned to secure care facilities than females (Webb, 2006). Regarding poverty, Sampson and Laub (1993) found a connection between economic disadvantage and increased rates of juvenile justice processing. Links have also been drawn between poverty and juvenile delinquency using individual-level variables. Some studies have identified poverty's negative impact on family processes, which contribute to adolescent emotional and behavioral problems (Conger et al., 1994; Jarjoura et al., 2002; Sampson and Laub, 1994). On the other hand, some studies suggest that judges' dispositions are only marginally influenced by individual characteristics (Applegate et al., 2002; Cauffman et al., 2007; Guevara et al., 2008). In an Ohio sample, Applegate et al. (2002) found that judges made decisions based on legal factors and rarely considered the individual characteristics (race, age, gender, etc.) of the juvenile defendants. 


\section{Limitations of Previous Research}

No consistent model has been developed to predict disposition outcomes for juvenile delinquents. Previous research identified that judges' decisions to incarcerate youth may be based on a variety of individual, legal and environmental factors. This study builds on previous research by examining juvenile sentencing at the parish level for a Deep South state. In the study state, parishes are equivalent to counties. Parish-level characteristics predicted to influence juvenile sentencing include urban designation, race and poverty. Previous studies have failed to use racial composition and poverty rates as parish/county level predictors and instead have utilized the juvenile defendant as the unit of analysis. This study uses parish/county-level data as the unit of analysis to determine if juvenile dispositions could be predicted by parish-level characteristics alone.

\section{Materials and Methods}

\section{Data Source and Sample}

A secondary data analysis of the number of youths placed in secure care per parish in Louisiana was conducted based on statistics from the Louisiana Commission on Law Enforcement's (LCLE) 2007 Annual Report. The unit of analysis was the parish and data from all parishes in the state were used in the analysis $(\mathrm{N}=64)$. The LCLE obtained this data from the FBI Uniform Crime Reports for law enforcement agencies in Louisiana. Specifically, the available data contained the number of juveniles under the Louisiana Office of Juvenile Justice (LAOJJ) jurisdiction per parish (LCLE, 2007). Youth under the jurisdiction of LAOJJ have been formally petitioned in court and adjudicated as delinquent. The LCLE (2007) report provided the total number of juveniles who were placed in long-term secure care facilities along with the parish of adjudication. The data was analyzed for the year 2003 because this was the most recent data that was available.

Parish-level data from the USCB (2000) were matched to the parish-level, secure confinement adjudications in order to construct predictors for the analysis. The predictor variables from the U.S. Census included geographic location (urban/suburban vs. rural), percent non-white and percent below the poverty threshold.

\section{Purpose}

The purpose of this study was to examine the effects of environmental factors on juvenile court dispositions in a Deep South state. This study sought to determine if parish level variables such as geographic location (urban/suburban vs. rural parishes), racial composition and poverty rates predicted long-term, secure-care, juvenile dispositions.

\section{Hypotheses}

This study hypothesized that an urban/suburban parish designation was predictive of higher rates of harsh dispositions in comparison to a rural parish designation. This hypothesis was based on Feld (1991) justice by geography concept, which posited that urban and suburban courts tended to render harsher dispositions than rural courts due to their formality and bureaucratization.

Second, it was hypothesized that parishes with higher percentages of non-whites would result in higher rates of secure dispositions. The rationale for this hypothesis was based on findings from a 2006 study that suggested a juvenile's race played an influential role when rendering harsh dispositions (Webb, 2006). Although Webb's (2006) study measured race as an individual-level predictor, this study speculated that race as a parish-level variable could also predict harsh dispositions.

Lastly, the authors hypothesized that juvenile court judges were more likely to render harsh dispositions in parishes with high poverty rates. Rationale for this hypothesis was based on previous research, which indicated poverty as a correlate of juvenile delinquency (Conger et al., 1994; Jarjoura et al., 2002; Sampson and Laub, 1994). Based upon previous research, this study posed that high parish poverty rates were predictive of higher rates of harsh juvenile dispositions.

\section{Measures}

\section{Dependent Variable}

The juvenile harsh disposition rate was the dependent variable of this study. The variable was measured by calculating the rate of juveniles placed in long-term, secure care facilities per 1,000 juveniles in each parish. The study examined 2003 data from the 2007 Annual Report of the Louisiana Commission on Law Enforcement because this report contained the most recent data on secure-care dispositions. The number of juveniles per parish was obtained from 2000 U.S. Census data and accounted for all juveniles aged 10-19. These age groups were chosen due to interval level age ranges (The data source from the U.S. Census Bureau presented age ranges per parish in intervals of 5-9, 10-14 and 1519. Since juveniles aged 10-16.5 are under LAOJJ jurisdiction, this author chose these age ranges while understanding the potential for inflated values) in the Census Bureau data.

\section{Independent Variables}

Independent variables included geographic location, racial composition and poverty rates. Data for each came from the U.S. Census Bureau. The first variable involved the geographic location of the juvenile court. Each parish was placed into one of three subcategories entitled urban, 
suburban and rural. Parishes located in a Standardized Metropolitan Statistical Area (SMSA) that had one city of at least 100,000 and a juvenile population (ages 1019) of at least 50,000 was categorized as urban. Similarly, parishes located in an SMSA that had at least one city of 25,000-100,000 and a juvenile population of 7,500-50,000 was categorized as suburban. Parishes located outside an SMSA, with no city of greater than 25,000 and less than 7,500 juveniles were categorized as rural. Urban and suburban parishes were collapsed into one variable (urban/suburban) due to the low number of urban parishes in the state. Urban and suburban parishes were coded as one whereas rural parishes were coded as zero.

The next variable involved the racial composition of each parish in Louisiana: The percentage of non-white persons residing in each parish. In the 2000 decennial census of the population of the United States, participants were asked to select their race from a list of options. If they selected "white alone", they were coded ' 0 ' for the non-white variable. Their response was coded " 1 " for this variable if they selected any of the other options which included Black or African American alone, American Indian and Alaska Native alone, Asian alone, Native Hawaiian and Other Pacific Islander alone, some other race alone, or two or more races (USCB, 2002). The third and final variable, the parish poverty rate, was defined as the percent of total persons in each parish whose 1999 income was below the poverty threshold for families of the same size and with the same number of children (USCB, 2002). In 1999, the poverty threshold was $\$ 11,483$ for a family of three with one child and whose householder was under the age of 65 (USCB, 2002).

\section{Results}

\section{Descriptive Statistics}

Geographic location was measured in terms of urban, suburban and rural parishes. Four parishes were classified as urban, 15 as suburban and 45 as rural. Urban parishes accounted for a total population of $1,605,153(36 \%)$ and a juvenile population of 239,567 (34\%). Suburban parishes consisted of a total population of 1,580,298 (35\%) and a juvenile population of 256,462 (36\%). The 45 rural parishes accounted for a total population of $1,283,416(29 \%)$ with a juvenile population of $207,878(30 \%)$. Due to the low number of urban parishes in the state, the regression model required urban parishes to be combined with suburban parishes to provide sufficient degrees of freedom $(\mathrm{df}=18)$. Thus, comparisons were drawn between urban/suburban and rural parishes. In summary, 19 parishes were classified as urban/suburban with a total population of $3,185,451$
(71\%) and juvenile population of 496,029 (70\%). These descriptive statistics of population characteristics can be found in Table 1.

Since Louisiana parishes made up the units of analysis, a sample size of 64 parishes was obtained $(\mathrm{N}=64)$. According to the 2000 census, Louisiana's total population consisted of 4,468,867 with a juvenile population (10-19 years old) of approximately 703,907. Minorities accounted for about $34 \%$ of the population, where African Americans made up the majority of this group. Hispanics, Asians, American Indians and other groups accounted for less than $4 \%$ of the entire Louisiana population (USCB, 2000). In regard to poverty, an average of $22 \%$ of the entire Louisiana population fell below the poverty line according to USCB (2000).

A total of 898 secure dispositions were rendered by juvenile court judges in 2003 according to data from the Louisiana Commission on Law Enforcement (n.d.). This dependent variable was measured by the rate of secure dispositions per 1,000 juveniles in each parish. The minimum rate of secure dispositions per parish was zero and the maximum rate of secure dispositions was 6.91 . The mean for these values was 1.30 ( $\mathrm{SD}=0.98)$. Descriptive statistics are listed in Table 2.

\section{Multivariate Analysis}

A correlation matrix and multiple linear regression analysis were used to illustrate the relationship between juvenile justice dispositions and parish-level characteristics. The correlation matrix is provided in Table 3 and a summary of the multiple linear regression model is provided in Table 4. The regression model was run in SPSS to determine whether geographic location (urban/suburban vs. rural), percent non-white and/or percent below poverty at the parish-level would predict rates of harsh (i.e., secure care) dispositions. An $R^{2}$ value of 0.246 was obtained, but only the percent below poverty level variable $(r=0.5 ; p<0.01)$ significantly predicted harsher juvenile dispositions. While there was a moderate bivariate correlation between percent non-white and high poverty levels $(r=0.664$; $\mathrm{p}<0.001$ ), the absence of a relationship in the multivariate model indicates that poverty rates mediated the relationship between the percent nonwhite and the issuance of harsh dispositions.

To ensure validity of the model, a residual analysis was conducted to identify outliers. Only one parish was identified due to its high rate of harsh dispositions, a rate of 6.91 secure confinements per 1,000 juveniles. To mitigate the influence of this Parish, the mean was imputed in place of the true value $($ Mean $=1.3$ ) and another regression was run. Similar results were obtained as the percent below poverty variable remained the only significant predictor $(\mathrm{r}=0.42 ; \mathrm{p}<0.05)$. 
Table 1. Summary of parish population characteristics

\begin{tabular}{lllllr}
\hline & Total & Total & Juvenile & Total juvenile \\
population & population (\%) & population (\%) \\
\hline Urban & Parishes & $1,605,153$ & 36 & 239,567 & 34 \\
Suburban & 4 & $1,580,298$ & 35 & 256,462 & 36 \\
Rural & 45 & $1,283,416$ & 29 & 207,878 & 30 \\
Total & 64 & $4,468,687$ & 100 & 703,907 & 100 \\
\hline
\end{tabular}

Table 2. Summary of descriptive statistics for parish-level rates of secure-care dispositions, percent non-white and percent below poverty

\begin{tabular}{lcccc}
\hline & Mean & Standard deviation & Minimum & Maximum \\
\hline Secure dispositions & 1.30 & 0.98 & 0.00 & 6.91 \\
Non-white & 33.87 & 14.06 & 5.70 & 71.90 \\
Below poverty & 21.96 & 6.26 & 9.70 & 40.50 \\
\hline
\end{tabular}

Note. One outlier Parish was included in the original regression model and is therefore included in this summary of descriptive statistics $(\mathrm{N}=64)$

Table 3. Correlation matrices predicting secure-care dispositions with urban/suburban location, percent non-white and percent below poverty

\begin{tabular}{lllll}
\hline & 1. Secure-care dispositions & 2. Urban/suburban & 3. Non-white & 4. Below poverty \\
\hline 1 & 1.000 & -0.129 & $0.382^{* *}$ & $0.473^{* * *}$ \\
2 & -0.129 & 1.000 & -0.155 & $-0.522^{* * *}$ \\
3 & $0.382^{* *}$ & -0.155 & 1.000 & $0.664^{* * *}$ \\
4 & $0.473^{* * *}$ & $-0.522^{* * *}$ & $0.664^{* * *}$ & 1.000 \\
\hline
\end{tabular}

Note. $\mathrm{N}=64 ;{ }^{*} \mathrm{p}<0.05 .{ }^{* * \mathrm{p}<0.01 .} * * * \mathrm{p}<0.001$

Table 4. Multiple regression analysis predicting harsh juvenile dispositions with geographic location, percent non-white and percent below poverty

\begin{tabular}{llllll}
\hline Predictors & $\mathrm{B}$ & Std. Error & Beta & Sig. & Partial (r) \\
\hline Intercept & -0.685 & 0.521 & - & 0.194 & - \\
Urban/Suburban & 0.306 & 0.294 & 0.144 & 0.302 & 0.133 \\
Non-white & 0.005 & 0.011 & 0.073 & 0.645 & 0.060 \\
Below Poverty & $0.078^{*}$ & 0.029 & & 0.500 & 0.334 \\
$\mathrm{~N}=64$ & & & & \\
Model fit statistics & & & & \\
$\mathrm{R}^{2}=0.246$ & & & & \\
$\mathrm{~F}(3,63)=6.512^{*}$ & & & & & \\
\hline
\end{tabular}

Note. Dependent Variable: Secure dispositions per 1,000 juveniles. $\mathrm{N}=64$. Urban-Suburban refers to dummy coded variable (urban suburban parishes $=1$; Rural parishes $=0$ ). Non-white refers to percent of non-white persons per parish. Below Poverty refers to total number of individuals per parish that fall below the poverty line; ${ }^{*} \mathrm{p}<0.05$

\section{Discussion}

This study examined the relationship between parish level characteristics and the prevalence of harsh juvenile court dispositions in a Deep South state. The authors hypothesized that more severe dispositions would occur in urban/suburban parishes with high rates of poverty and high percentages of minorities. The results, however, did not support all predictions. Findings indicated that high poverty rates predicted high rates of harsh juvenile dispositions. Thus, geographic location in urban or suburban parishes and percent non-white per parish were not found to significantly predict harsher juvenile disposition rates.

Compared to previous research, this study produced mixed results and further contradictions. Findings contradicted Feld (1991) concept of justice by geography because urban/suburban locations did not significantly predict the severity of dispositions. However, when percent non-white and percent below the poverty level were controlled, urban/suburban parishes were correlated with harsh disposition rates. This result, although insignificant, was similar to Feld's finding that indicated less severe dispositions in rural counties (Feld, 1991). Results from this research also shared similarities with Sanborn's 2001 study which found that the urban designation of court locations did not affect judges' perceptions and therefore did not predict disposition severity (Sanborn, 2001).

With regard to the percentage of non-white residents per parish, this study shared similarities with previous literature. Guevara et al. (2008) found that race did not significantly predict harsh sentencing in a comparison of two Midwestern courts. A similar study 
compared two urban courts and found that race was unrelated to juvenile court dispositions when analyzed as an individual-level variable (Cauffman et al., 2007). It should be noted, however, that these previously mentioned studies used race as individuallevel variables rather than county/parish level variables like that used in the current study. In contrast, Dejong and Jackson (1998; Webb, 2006) found differing results in regards to race. Dejong and Jackson (1998) found that African American youth received harsher dispositions in urban courts and that these youth were also more likely to be placed in secure facilities in rural courts. Webb (2006) found that race, as an individual-level predictor, had the most influence on juvenile court decisions when controlling for legal and non-legal factors. In the current study, harsh juvenile disposition was not predicted by percentage of non-white residents in the parish.

Results from this study mirrored the mixed results from previous literature in regard to parish poverty rates. Findings showed some similarities with a 2003 study, which found that poverty and racial inequality, both individual-level variables, were predictive of increased rates of juvenile justice processing (Sampson and Laub, 1993). In contrast, Cohen and Kluegel (2001) found that social class and poverty did not predict harsh juvenile sentencing when measured as individual-level variables. When using poverty rates as a county-level variable, Sampson and Laub (1993) revealed that a county's wealth and resources did not explain much variance in juvenile court case processing.

Although limited research has studied poverty's direct effects on juvenile court dispositions, many studies have linked poverty to juvenile delinquency. Sampson and Laub (1994) found that poverty inhibited informal social controls, thereby causing increased rates of juvenile delinquency. Conger et al. (1994) studied economic stress and found that this stress causes hostile parent-child interactions. These hostile interactions negatively affect childhood development, which increased the likelihood for juvenile delinquency (Conger et al., 1994). In an ethnographic study, researchers studied the timing and persistence of poverty using 14 years of longitudinal data (Jarjoura et al., 2002). Findings indicated that children exposed to long-term poverty were more likely to engage in delinquent behaviors.

One possible explanation for high poverty parishes' correlation with harsh juvenile dispositions was addressed in a 2002 study (Applegate et al., 2002). Applegate et al. (2002) found that juvenile court judges were more likely to incarcerate youth when no other options were available. Thus, parishes with higher poverty rates may offer fewer juvenile justice resources, leaving judges fewer options when rendering dispositions. Further analysis on social service resources in each parish must take place to better understand this phenomenon.

Another explanation involves poverty's negative effects on family processes, which in turn, increases the likelihood of juvenile delinquency (Conger et al., 1994; Sampson and Laub, 1994). Studies have demonstrated poverty's relationship with poor supervision, weak parent-child attachment and coercive or harsh discipline techniques (Conger et al., 1994; Sampson and Laub, 1994). These family processes are known correlates of juvenile delinquency and may provide implications regarding the importance of family involvement in juvenile court dispositions (Sampson and Laub, 1994). However, the studies that linked poverty to juvenile delinquency did not examine poverty as a parish/county level variable and failed to include information related to dispositions. Therefore, the processes are unclear in understanding how parishlevel poverty rates affect harsh juvenile dispositions. Perhaps the presumed lack of community resources in these parishes has created barriers to providing family-oriented treatment interventions that address and prevent juvenile delinquency. Future studies are warranted on this subject matter.

\section{Limitations}

Although this study sought to predict juvenile court dispositions using only parish level characteristics, future studies should expand on the number of variables that were not included in the regression model. Previous studies identified that legal, individual and environmental variables predict harsh dispositions (Applegate et al., 2002; Cauffman et al., 2007; Dejong and Jackson, 1998; Feld, 1991; Guevara et al., 2008; Sampson and Laub, 1993; Webb, 2006). Legal factors like severity of crimes, prior legal charges and representation by legal counsel were not examined in this study. Individual-level variables like age, gender, family support and developmental maturity were also left out.

Limitations existed with regard to external validity as well. This study examined parishes in Louisiana, a state that may not be representative of others across the U.S. Louisiana's juvenile courts have a history of relying on detaining youth across locales (LAOJJ, n.d.) and, recent reforms (Louisiana Juvenile Justice Reform Act of 2003) and federal oversight (the 1998 lawsuit was dropped in 2006 due to Louisiana's reforms) may affect the study's generalizability.

\section{Conclusion}

This study used Louisiana Parishes as units of analysis to determine whether geographic location, 
percentage of non-whites per parish and poverty rates were predictive of harsh juvenile disposition rates. Results indicated that high parish poverty rates were the only significant predictor of increased rates of harsh juvenile dispositions and thus, Feld (1991) concept of justice by geography was not supported. However, findings from this study provided implications for juvenile justice policies and future research.

\section{Policy Implications}

A careful analysis of funding priorities should take place within the juvenile justice system to address high poverty parishes/counties that may have inadequate community-based treatment options for juvenile offenders. If poor parishes/counties are found to lack appropriate resources, then state and local leaders must take steps to implement evidenceinformed interventions that require family involvement and individualized treatment planning. On a local level, collaborative efforts should take place between the justice system, city officials, social service providers and other community stakeholders to address juvenile delinquency and adopt evidencebased programs to prevent subsequent offending.

Further, statewide comprehensive databases should be created to track juvenile court dispositions at the county/parish level. These databases would serve in two capacities, (1) to increase accountability and transparency within juvenile courts and (2) to enhance the validity on juvenile disposition research. The databases should provide disposition information as well as a wide array of individual, legal and environmental characteristics of the offender. By continuously collecting and analyzing this data, researchers can achieve a greater understanding of the decision-making process behind juvenile dispositions.

\section{Future Research}

Future research should aim to understand how parish/county poverty levels impact juvenile justice decision-making. A more thorough examination of impoverished parishes/counties may help determine whether inadequate juvenile justice resources are linked to harsher dispositions. Future studies should also include a combination of individual (e.g., gender and age), legal (e.g., prior offenses) and environmental (e.g., geographic location) variables. Severity of dispositions including secure placements, non-secure out-of-home placements, probation dispositions and total number of court referrals could also be included. Waivers to adult court must also be taken into consideration as these cases may warrant the most serious sentences.
Multilevel modeling should be considered in future research to allow an analysis of individual- and parishlevel predictor variables. Studies using multilevel modeling that include environmental, legal and individual predictors can provide more adequate direction for juvenile justice policymakers.

\section{Author's Contributions}

Dr. Bret Blackmon developed the research idea and served as the primary author. Dr. Daphne Cain served as a contributing author. Dr. Michelle Livermore served as a contributing author and a data-analysis consultant.

\section{Ethics}

There are no competing or conflicts of interest with regard to this manuscript. No funding sources are associated with this manuscript.

\section{References}

Applegate, B.K., M.G. Turner, J.B. Sanborn, E.J. Latessa and M.M. Moon, 2002. Individualization, criminalization, or problem resolution: A factorial survey of juvenile court judges' decisions to incarcerate youthful felony offenders. Just. Q., 17: 309-331. DOI: 10.1080/07418820000096341

Cauffman, E., A.R. Piquero, E. Kimonis, L. Steinberg and L. Chassin et al., 2007. Legal, individual and environmental predictors of court disposition in a sample of serious adolescent offenders. Law Human Behav., 31: 519-535.

DOI: $10.1007 / \mathrm{s} 10979-006-9076-2$

Cohen, L.E. and J.R. Kluegel, 2001. The detention decision: A study of the impact of social characteristics and legal factors in two metropolitan juvenile courts. Soc. Forces, 58: 146-162.

DOI: $10.1093 / \mathrm{sf} / 58.1 .146$

Conger, R.D., X. Ge, G.H. Elder, F.O. Lorenz and R.L. Simons, 1994. Economic stress, coercive family process and developmental problems of adolescents. Child Dev., 65: 541-561. DOI: 10.2307/1131401

Dejong, C. and K.C. Jackson, 1998. Putting race into context: Race, juvenile justice processing and urbanization. Just. Q., 15: 487-504.

DOI: 10.1080/07418829800093851

Feld, B., 1991. Justice by geography: Urban, suburban and rural variations in juvenile justice administration. J. Criminal Law Criminol., 82: 156-210. DOI: $10.2307 / 1143795$

Guevara, L., D. Herz and C. Spohn, 2008. Race, gender and legal counsel: Differential outcomes in two juvenile courts. Youth Violence Juvenile Just., 6: 83-104. DOI: $10.1177 / 1541204007303939$ 
Jarjoura, G.R., R.A. Triplett and G.P. Brinker, 2002. Growing up poor: Examining the link between persistent childhood poverty and delinquency. J. Quantitative Criminol., 18: 159-187.

DOI: 10.1023/A:1015206715838

Johnson, J.B. and P.E. Secret, 1995. The effects of court structure on juvenile court decisionmaking. J. Criminal Just., 23: 63-82. DOI: 10.1016/0047-2352(94)00045-X

LCLE, 2007. Louisiana juvenile justice and delinquency advisory board 2007 annual report. Louisiana Commission on Law Enforcement.

Louisiana Juvenile Justice Reform Act, 1225 LA (2003). Retrieved from http://www.legis.state.la.us/leg_docs/03RS/CVT10/ OUT/0000KTKP.PDF

Louisiana Office of Juvenile Justice (n.d.). History of juvenile justice in Louisiana. Retrieved from http://ojj.la.gov/index.php?page $=$ sub\&id $=229$

NCJJ, 2005. State profiles: Louisiana. National Center for Juvenile Justice.

Puzzanchera, C., 2009. Juvenile arrests 2007 (NCJ Report 225344). U.S. Office of Juvenile Justice and Delinquency Prevention.

Puzzanchera, C. and B. Adams, 2011. Juvenile arrests 2009 (NCJ Report 236477). U.S. Office of Juvenile Justice and Delinquency Prevention
Puzzanchera, C. and S. Hockenberry, 2013. Juvenile Court Statistics 2010. National Center for Juvenile Justice. Pittsburgh, PA.

Sampson, R.J. and J.H. Laub, 1993. Structural variations in juvenile court processing: Inequality, the underclass and social control. Law Soc. Rev., 27: 285-309. DOI: $10.2307 / 3053938$

Sampson, R.J. and J.H. Laub, 1994. Urban poverty and the family context of delinquency: A new look at structure and process in a classic study. Child Dev., 65: 523-540. DOI: $10.2307 / 1131400$

Sanborn, J.B., 2001. A parens patriae figure or impartial fact finder: Policy questions and conflicts for the juvenile court judge. Criminal Just. Policy Rev., 12: 311-332. DOI: 10.1177/0887403401012004004

Snyder, H.N. and M. Sickmund, 2006. Juvenile offenders and victims: 2006 national report. ERIC.

USCB, 2002. Census 2000 summary file 3 technical documentation. U.S. Census Bureau.

USCB, 2000. State and county quickfacts. U.S. Census Bureau.

Webb, P., 2006. Predicting pre-adjudicatory detention decisions: An investigation of legal and extralegal factors. J. Ethnicity Criminal Just., 4: 37-50.

DOI: $10.1300 / J 222$ v04n04 03 